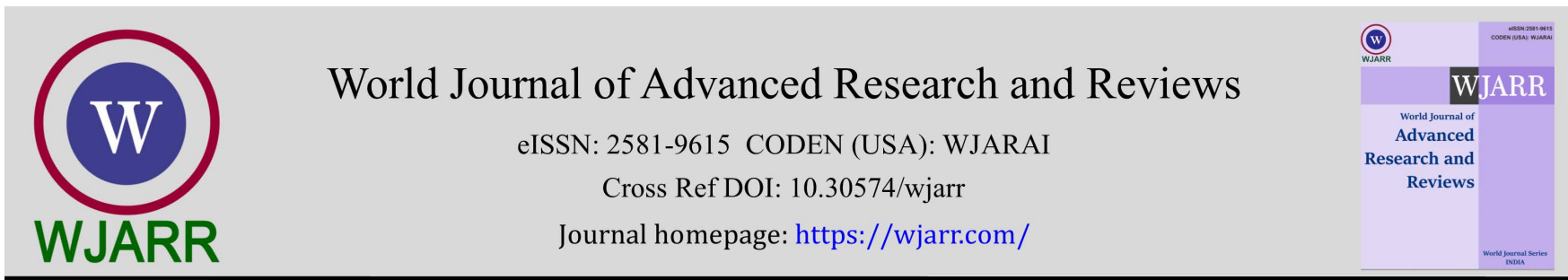

(RESEARCH ARTICLE)

Check for updates

\title{
Investigation of the effects of the interaction between pets and children on development and psychology during the covid-19 pandemic period
}

\author{
Emre Aydemir 1, ${ }^{*}$, İnci Bilge 2, Gkioulsach Chatzisouleiman ${ }^{3}$, Meltem Musul 4 and Tuğçe Özel 5 \\ ${ }^{1}$ Department of Animal Science, Faculty of Agriculture, Akdeniz University, Antalya-Turkey. \\ 2 Department of Electricity and Energy, Vocational School of Technical Sciences, Mehmet Akif Ersoy University, Burdur, \\ Turkey. \\ ${ }^{3}$ Department of Curriculum and Instruction, Faculty of Education, Gazi University, Ankara, Turkey. \\ ${ }^{4}$ Department of Preschool Education, Faculty of Education, Akdeniz University, Antalya-Turkey. \\ ${ }^{5}$ Eskisehir Anadolu University, Department of Business Administration, Faculty of Business, Eskisehir, Turkey.
}

World Journal of Advanced Research and Reviews, 2021, 10(01), 203-209

Publication history: Received on 13 March 2021; revised on 15 April 2021; accepted on 18 April 2021

Article DOI: https://doi.org/10.30574/wjarr.2021.10.1.0160

\begin{abstract}
With the increasing number of COVID-19 virus cases causing pandemic effects worldwide, various measures such as restrictions have been taken. During these precautions, it has caused various stress-related problems in children who do not have the habit of staying home for a long time. Children were school life and being away from friends cause various problems such as sleep disorder, anxiety, depression, fear, anger, stress, sensitivity, feeling lonely. It is known that pets play a large part in the ability of children to cope with such problems. In this study, the relationship between the sense of responsibility, sleep disorder, hyperactivity and anger and pet owner during the covid-19 pandemic period of participating children was examined. In addition, the study was examined the relationship between attachment to the pet types of children during the covid-19 pandemic. In children with pets; when the relationship between animal types and attachment is examined; dog as pets for the majority of men; girls were found to have a cat. In the study, the sense of responsibility of children who own a pet; it was found that it is more developed than those who do not own a pet. When the sleep pattern disorder was examined, It was determined that it is more common in children who do not have a pet. In addition, it was found that children who do not have a pet are more hyperactive and angry. In this study, it was aimed to provide information about the effects of interaction between pets and children on development and psychology during the covid-19 pandemic.
\end{abstract}

Keywords: Child development; Covid-19; Pet; Psychology

\section{Introduction}

Covid-19 (SARS-CoV-2), a worldwide pandemic effect, first appeared in Wuhan, China, in December 2019 [1]. With its spread in a short time, it was affected the whole world. The world health organization declared Covid-19 as a global epidemic on March 11, 2020 [2]. Various measures was taken to prevent this epidemic. With the increase in the number of cases, restrictions and quarantine measures were taken. During these measures, various stress-related problems started to arise in children who do not have the habit of staying home for a long time. Among these problems, problems such as sleep disorder, anxiety, depression, fear, neurodevelopmental disorders, biological deterioration of homeostasis, sensitivity to the effects of stress, hyperactivity disorder, hyperkinetic disorder, attention deficit occur in different age groups, especially in children $[3 ; 4 ; 5 ; 6]$. In addition, it is observed that they react to environmental changes due to restrictions, prevent socialization, excessive exposure to social media, anxiety, aggression and loneliness

\footnotetext{
* Corresponding author: Emre Aydemir

Department of Animal Science, Faculty of Agriculture, Akdeniz University, Antalya-Turkey.
}

Copyright (c) 2021 Author(s) retain the copyright of this article. This article is published under the terms of the Creative Commons Attribution Liscense 4.0. 
[3; 4; 5]. Especially during the Covid-19 pandemic, it is among the factors that cause children to feel lonely due to their school life and being away from their friends [7; 4; 5]. Pets that help us cope with these; It contributes to increase the quality of life by helping people to increase their social support, their ability to cope with stress, and to eliminate negative social behaviors such as agonistic interactions [8; 9].

In the studies conducted, it is stated that children generally prefer cats and dogs as domestic animals. Reasons for this include the fact that the child communicates and plays with a dog or a cat, is easier than playing with a fish or canary, and is more interacting with other types of pets. Especially girls and boys; It is known that they attach to their pets at an early age and see them as a friend [10]. In some studies, it was observed that girls are more dependent on their pets than boys. Also, not only in breeds like cats and dogs; It was observed that girls are more dependent on other types of pets [10]. It is stated that the attachment of children to their pets, various responsibilities such as care, feeding and empathy contribute to their ability [10]. Especially attachment to pets is observed in young children [11; 12]. For example; In a study conducted by Melson (1991), it was stated that attachment to pets after the age of 13 tends to decrease. In a study conducted by the American Veterinary Medical Association; It was reported that $70 \%$ of all households with children less than 6 years old and 78\% of all households with children older than 6 years had pets [11; $12 ; 13 ; 25]$.

Family is one of the most important factors in gaining animal love in children. Children spend time like friends with pets owned by families. A child who grows up in a family that knows the needs and responsibilities of animals gains positive effects from this attitude $[14 ; 15 ; 16]$. When the effects of these gains on children are examined; learning, development, motivating, enhancing performance, sense of responsibility, independence, self-confidence, positive behavior development in terms of other autonomous traits, improved cognitive executive function through speculation, stress reduction and social support, gaining cognitive, physical, creative, problem-solving ability, It has been observed that social and cognitive functions support development, help children enrich their vocabulary, acquisition of reading skills, social functionality and academic competence, emotional stability in school and attitudes towards school [17; 18; 19; $20 ; 21 ; 22 ; 23 ; 24 ; 26 ; 27]$. It was observed that children who grow up with pets show higher levels of self-esteem and become more socially competent adults than children who do not grow up with pets [28]. Also; It is known that overcoming fears, controlling anger, sharing, increasing empathy, tolerance, self-control and autonomy, love of friendships, increased social interaction and communication skills, hormonal effects also play a role $[10 ; 13 ; 14 ; 15 ; 28$; $29 ; 30 ; 31]$.

\section{Material and methods}

In this study, in the 0-3, 3-6, 6-9 and 9-12 age range; it was realized with a total of 266 participants, 137 girls and 129 boys. Participating children were randomly selected by considering only age criteria. The questions directed to the participating children and their families were answered together. The relationship between the sense of responsibility, sleep disorder, hyperactivity and anger and pet owner during the covid-19 pandemic period of the participating children was examined. In addition, the study examined the relationship between attachment to the pet types of children during the covid-19 pandemic. The findings obtained from the study were made using SPSS statistical software for statistical analysis.

\section{Results}

Participating children in the study; they stated that they were cats, dogs, birds, fish and other kinds of domestic animals. While $45.11 \%$ of the children in the study had pets; $54.89 \%$ it was determined that he did not have any animals he owned. While $51.82 \%$ of the children who have a pet in the study are girls; $37.98 \%$ are boy participants. In the study, boys who have the most pets, depending on gender, are between the ages of 6-9. The age range of girls, who have the most pets, was found to be 3-6 years old.

Table 1 Different age ranges and pet ownership relationship in children.

\begin{tabular}{|c|c|c|c|c|}
\hline & 0-3 Age & 3-6 Age & 6-9 Age & 9-12 Age \\
\hline$\widehat{\jmath}$ (Boy) Pet Owner & 7 & 21 & 12 & 9 \\
\hline ठ (Boy) Without Pet & 16 & 13 & 25 & 16 \\
\hline o (Girs) Pet Owner & 14 & 26 & 18 & 13 \\
\hline + (Girs) Without Pet & 21 & 12 & 14 & 19 \\
\hline
\end{tabular}


The girls had $43.66 \%$ cat, $25.35 \%$ dog, $12.68 \%$ fish, $15.49 \%$ bird and $2.81 \%$ other pet types as pets. The boys had $28.57 \%$ cat, $42.86 \%$ dog, $6.12 \%$ fish, $14.22 \%$ bird and $8.56 \%$ other pet types.

Table 2 Pet species and their owners gender relationship.

\begin{tabular}{|l|l|l|l|l|l|}
\hline & Cat & Dog & Fish & Bird & Other Types of Pets \\
\hline+ (Girs) & 31 & 18 & 9 & 11 & 2 \\
\hline \multirow{O}{*}{ (Boy) } & 14 & 21 & 3 & 7 & 4 \\
\hline
\end{tabular}

While $45.11 \%$ of their children in the study have a pet; $54.89 \%$ does not have a pet. In the study, children with pets; $85.83 \%$ sense of responsibility, $14.16 \%$ sleep disorder, $21.66 \%$ hyperactivity and $25.83 \%$ anger were observed. It was observed that $40.41 \%$ of the children who do not have pets had a sense of responsibility, $48.63 \%$ had sleep disorder, $71.92 \%$ had hyperactivity and $58.90 \%$ had anger.

Table 3 Pet relationship with criteria.

\begin{tabular}{|c|c|c|c|c|}
\hline & Sense Of Responsibility & Sleep Disorder & Hyperactivity & Anger \\
\hline I $^{\wedge}$ (Girs, Boy) Pet Owner & $85,83 \%$ & $14,16 \%$ & $21,66 \%$ & $25,83 \%$ \\
\hline q $\partial^{\lambda}$ (Girs, Boy) Without Pet & $40,41 \%$ & $48,63 \%$ & $71,92 \%$ & $58,90 \%$ \\
\hline
\end{tabular}

In the study, a significant difference was found between the sense of responsibility of the children who own a pet and the group who did not have a pet. It was determined that children who have pets have a more developed sense of responsibility. When the sleep disorder was examined, it was observed that there was a significant difference in children who did not have a pet. In addition, these children were found to be more hyperactive and angry.

\section{Discussion}

Pets are known as close friends of all age groups, especially children. In recent years, it has been used for therapeutic purposes of animals in the fields of nursing, medicine and psychotherapy [32]. In some studies on adults; It has been observed that if they are friends with animals, they normalize the problems in heart rate and contribute to the reduction of the effects of problems such as anxiety and depression [3;33;34]. When the interaction of children with animals is examined; It has been found that stress decreases, attention deficit / hyperactivity and behavioral disorders in children contribute to the reduction [35; 36]. In addition, it was observed that it helps children with Down syndrome increase their positive behaviors [37]. In the study conducted by Güle and Özkan (2013), they examined the effects of children aged 4-6 on their development while living with a pet at home [15]. In the study, they was reported that keeping a pet at home contributed positively to the psychological development of children. In the study by Martin and Jennifer (2002), they quantitatively examined the effects of interaction with dogs on children with pervasive developmental disorders (PDD) characterized by a lack of social communication and ability [14]. In the study findings, it was stated that interaction with dogs in the social environment of children was beneficial and animal assisted therapy was an appropriate therapy method. Law and Scott (1995), who conducted a similar study; Redefer and Goodman (1989) and Nathanson et al. (1997) obtained similar results [38; 39; 40]. In the study conducted by Daly and Morton (2003), they examined the relationship between pet preference and empathy [41]. When the study examines some of the general findings about dogs and cats; Children who preferred both dogs and cats (Pet Preference Inventory) reported higher empathy than those who only preferred cats or dogs. Researchers was found that those with both dogs and cats had higher empathy than those who had only dogs, only cats, or none. In addition, those who are highly attached to their pets (Lexington Pet Attachment Scale) reported higher empathy ability and empathy and positive attitude (Pet Attitude Scale) compared to those who were less attached. They were observed that girls significantly more empathetic than boys. In another study conducted in a similar way; Beth Daly and Morton (2006) conducted a questionnaire to examine the relationship between human-animal interactions and empathy in terms of four-way - preference, ownership, attachment, and attitude [42]. In the study, they stated that there were a positive relationship between the empathy ability of individuals who have cats, dogs, or both. In the studies conducted by Baron-Cohen and Wheelright (2004), Gawronski and Privette (1997) and Eisenberg and Lennon (1983), girls who own a pet; stated that men have higher empathy skills [43; 44; 45]. In the results of a study on horses, Kaiser et al. (2004) were reported that children without physical or mental disabilities experienced a reduction in anger control and anger after participating in a five-day "therapeutic" riding program [46]. In the results of the study conducted by Paul and Serpell (1993), they were stated 
that the number of pets individuals have in their childhood is associated with the frugal behaviors they display in their adulthood. In addition, empathy scores of adults were reported to be correlated with the number of pets they had in childhood [47]. Robert et al. (1987) were examined the relationship between children (high school and university) and animals (pet ownership) [48]. The researchers used the Companion Animal Bonding Scale, an 8-item behavioral scale that describes the scope of child-animal activities. According to the results of the study, the relationship between selfconfidence and pet ownership in children was estimated as 0.82 and 0.77 , respectively, according to Cronbach's alpha estimates. They were stated that it showed significant correlations between the scores of the children and the contemporary attachment scale, between .39 and .40 points, respectively. According to the results of their study, Hydek et al. (1983) found that pet owners have higher social sensitivity and interpersonal trust criteria than those who do not [49]. Also, the quality of the relationship between the children and the pet; stated that it affects their social interactions. Melson (2003) was stated in the results of her study that the animals they have had a positive effect on perceptual, cognitive, social and emotional development [17]. In the study conducted by Vidović et al. (1999), they were examined the sensory characteristics of children with and without pets. In the study, they stated that $54.4 \%$ of the children have a pet $(26.2 \%$ of the children had a dog, $9.2 \%$ had a cat, and $19.0 \%$ had another pet). In the study conducted by us; while girls have $43.66 \%$ cats, $25.35 \%$ dogs and $30.98 \%$ other pet types as pets; It was determined that $28.57 \%$ of males adopt Cat, $42.86 \%$ dog and $28.5 \%$ other pet types [50]. In the results of the study conducted by Vidović et al. (1999); dog and cat owners stated that they found them more empathetic than those who did not [50]. In addition, when the socioemotional functions of the children and the pet attachment scale (non-owners, average and above, average and below) were examined, children who scored higher than average, empathy and prosocial orientation compared to children who scored below average on the attachment to non-owners and pets scale, they were reported that they got significantly higher scores on the scales. Westgarth et al. (2013) stated that 1021 primary school children aged 9-10 years prefer dogs as the most common and favorite pet [51]. In their study results, they were reported that they found a significant relationship between gender, ethnicity and socioeconomic status, pet ownership and sibling status and pet attachment level. In our study, it was found that boys most commonly adopted dogs as pets with a rate of $42.86 \%$. In the study conducted by Siegel (1995), they were stated that the dog or cat was mostly preferred as a pet [52]. However; It was reported that the least fish are preferred as pets. Similar results were obtained in the results of our study; The least preferred pet was determined to be fish. Purewal et al. (2017) were examined a wide variety of emotional relationships among children with pets in their study [53]. In the study, they were reported that children with pets provide behavioral, social developmental, cognitive, educational, perspective-taking skills, and intellectual developmental benefits. Beetz et al. (2011-2012), Gee et al. (2015) and Melson (2011) stated that dogs cause children's cortisol levels to decrease significantly faster. They also reported that after the stressor it dropped to low levels [28; 29; 30; 31]. Beetz et al. (20112012), Gee et al. (2015) and Melson (2011) reported in their study that enabling children with insecure and irregular attachment to interact with a friendly dog is beneficial in regulating physiological stress levels [28; 29; 30; 31]. In the study conducted by Roxanne and Joanne (2017), they were examined the relationships between pet types and childhood attachment, pet care, compassion for animals and attitudes towards animals [54]. In the study, it was found that attachment of children to their pets was in a statistically significant relationship; $83 \%$ of those who have pets stated that their pets make them happy, $76 \%$ stated that their pets are their best friends, $62 \%$ stated that they would be alone without their pets. Marsa-Sambol et al. (2017) reported that they obtained similar results in a study conducted by researchers. Similar results were obtained in our study; it was found that children see pets as close friends [55].

\section{Conclusion}

When examined in the studies carried out; it is stated that pets have positive effects on children. In the study carried out by us, the sense of responsibility of children who own a pet; it was observed to be higher in non-pet owners. It was determined that children who have pets have a more developed sense of responsibility. When the sleep disorder is examined. It has been observed that children who do not have pets have more sleep disorders than children with pets. In the study, it was stated by the participating families that the children saw pets as a friend. In addition, these children were found to be more hyperactive and angry.

\section{Compliance with ethical standards}

\section{Statement of informed consent}

Informed consent was obtained from all individual participants included in the study. 


\section{References}

[1] Sun, J., He, W.-T., Wang, L., Lai, A., Ji, X., Zhai, X., Li, G., Suchard, M. A., Tian, J., Zhou, J., Veit, M., \& Su, S. 2020. COVID19: epidemiology, evolution, and cross-disciplinary perspectives. Trends in Molecular Medicine, 20; 5.

[2] WHO (World Health Organization). 2020. Coronavirus disease 2019 (COVID-19) Situation Report - 51.

[3] Barker, S. B., \& Dawson, K. S. (1998). The effects of animal-assisted therapy on anxiety ratings of hospitalized psychiatric patients. Psychiatric Services, 29, 797-801.

[4] Gregory, A.M., \& Sadeh, A. (2016). Annual Research Review: Sleep problems in childhood psychiatric disorders a review of the latest science. Journal of Child Psychology and Psychiatry, 57, 296-317.

[5] Stroud. The Oxford Handbook of Stress and Mental Health. 2020. The stress sensitization model.

[6] Selye H., 1950, The Physiology and Pathology of Exposure to Stress Acta, Inc, Oxford, England

[7] Cluver, L., Lachman, J.M., Sherr, L., Wessels, I., Krug, E., Rakotomalala, S., Blight, S., Hillis, S., Bachman, G., Green, 0., \& Butchart, A. (2020). Parenting in a time of COVID-19. Lancet, 395, e64.

[8] Boissy A., Manteuffel G., Jensen M.B., R.O.Moe, B. Spruijt, Keeling L.J., Winckler C., B. Forkman, I.Dimitrov, J. Langbein, M. Bakken, I. Veissier, A. Aubert, 2007, Assessment of positive emotions in animals to improve their welfare Physiol. Behav., 92, pp. 375-397.

[9] Rodenburg T.B., Koene P., 2007, The impact of group size on damaging behaviours, aggression, fear and stress in farm animals Appl. Anim. Behav. Sci., 103, pp. 205-214.

[10] Levinson, B. M. 1984. Foreword. In Dynamic Relationships in Practice: Animals in Helping Professions, 1-20, ed. P. Arkow. Alameda, CA: Latham Foundation.

[11] Kellert, S. R. and Westervelt, M. 0. 1983. Children's Attitudes, Knowledge and Behaviors Toward Animals. Washington, D.C.: National Technical Information Service.

[12] Davis, J. H. and Juhasz, A. M. 1985. The pre- adolescent pet bond and psychological develop- ment. Marriage and Family Review 8: 79-94.

[13] Van Houtte, B. and Jarvis, P. A. 1995. The role of pets in preadolescent psychosocial develop- ment. Journal of Applied Developmental Psychology 16: 463-479.

[14] François Martin and Jennifer Farnum, 2002, Animal-Assisted Therapy for Children with Pervasive Developmental Disorders, WesternJournalofNursingResearch, 24(6),657-670.

[15] Figen Güle and Kadircan Özkan, 2013, ANIMAL LOVE IN CHILDREN journal of Teaching and Education, CD-ROM. ISSN: 2165-6266 : 2(1):61-65.

[16] McCardle, P., McCune, S., Griffin, J. A., \& Maholmes, V. (Eds.). (2011). How animals affect us: Examining the influences of human-animal interaction on child development and human health. American Psychological Association.

[17] Melson, G.F. 2003, Child development and the human-companion animal bond. Am. Behav. Sci., 47, 31-39.

[18] Le Roux, M.C.; Swartz, L.; Swart, E. 2014, The effect of an animal-assisted reading program on the reading rate, accuracy and comprehension of grade 3 students: A randomized control study. Child Youth Care Forum, 43, 655-673.

[19] Hall, S.S.; Gee, N.R.; Mills, D.S. 2016, Children reading to dogs: A systematic review of the literature. PLoS ONE, 11, e0149759.

[20] O'Haire, M.E.; Slaughter, V.; McKenzie, S.J.; 2013, McCune, S. Effects of animal-assisted activities with guinea pigs in the primary school classroom. Anthrozoös, 26, 445-458.

[21] Anderson, K.L.; Olson, M.R. 2006, The value of a dog in a classroom of children with severe emotional disorders. Anthrozoös, 19, 35-49.

[22] Svensson, A.S. 2014, The impact of the animals on children's learning and their development-A study of what children learn from and with pets: The example of dog and cat. Prob. Educ., 59, 77-85.

[23] Gee, N.R.; De, M.; Riley, W.; 2012, Belcher, J.M.; Grabski, J.L. The presence of a therapy dog results in improved object recognition performance in preschool children. Anthrozoos, 25, 289-300. 
[24] Gee, N.R.; Sherlock, T.R.; 2009, Bennett, E.A.; Harris, S.L. Preschoolers' adherence to instructions as a function of presence of a dog and motor skills task. Anthrozoös, 22, 267-276.

[25] Melson, G. F. 1991. Studying children's attach- ment to their pets: A conceptual and method- ological review. Anthrozoös 4(2): 91-99.

[26] Ling, D.S.; Kelly, M.; 2016, Diamond, A. Human-animal interaction and the development of executive functions. In The Social Neuroscience of Human-Animal Interaction; Freund, L.S., McCune, S., Esposito, L., Gee, N.R., McCardle, P., Eds.; American Psychological Association: Washington, DC, USA.

[27] Kidd, A.H.; Kidd, R.M. 1985, Children's attitudes toward their pets. Psychol. Rep., 57, 15-31.

[28] Beetz, A.; Julius, H.; Turner, D.;2012, Kotrschal, K. Effects of social support by a dog on stress modulation in male children with insecure attachment. Front. Psychol., 3, 352.

[29] Beetz, A.; Kotrschal, K.; Turner, D.C.; 2011, Hediger, K.; Uvnäs-Moberg, K.; Julius, H. The effect of a real dog, toy dog and friendly person on insecurely attached children during a stressful task: An exploratory study. Anthrozoös, 24, 349-368.

[30] Gee, N.R.; Friedmann, E.; Coglitore, V.; 2015, Fisk, A.; Stendahl, M. Does physical contact with a dog or person affect performance of a working memory task? Anthrozoös, 28, 483-503.

[31] Melson, G.F. 2011, Principles for human-animal interaction research. In How Animals Affect Us: Examining the Influence of Human-Animal Interaction on Child Development and Human Health; McCardle, P.M.S., Griffin, J.A., Maholmes, V., Eds.; American Psychological Association: Washington, DC, USA.

[32] Cole, K. M., \& Gawlinski, A. (2000). Animal-assisted therapy: The human-animal bond. Ameri- can Association of Critical-Care Nurses Clinical Issues, 11, 139-149.

[33] Friedmann, E., Katcher, A. H., Lynch, J. J., \& Thomas, S. A. (1980). Animal companions and one-year survival of patients after discharge from a coronary care unit. Public Health Reports, 95, 307-312.

[34] Anderson, W. P., Reid, C. M., \& Jennings, G. L. (1992). Pet ownership and risk factors for car- diovascular disease. Medical Journal of Australia, 157, 298-301.

[35] Hansen, K. M., Messinger, C. J., Baun, M. M., \& Megel, M. (1999). Companion animals alleviating distress in children. Anthrozoös, 12, 142-148.

[36] Katcher, A. H., \& Wilkins, G. G. (1998). Animal-assisted therapy in the treatment of disruptive behavior disorders in children. In L. Ante (Ed.), The environmental and mental health: A guide for clinicians. Mahwah, NJ: Lawrence Erlbaum.

[37] Limond, J. A., Bradshaw, J. W. S., \& Cormack, K. F. M. (1997). Behavior of children with learning disabilities interacting with a therapy dog. Anthrozoös, 10, 84-89.

[38] Law, S., \& Scott, S. (1995). Tips for practitioners: Pet Care: A vehicle for learning. Focus on Autistic Behavior, 10, 17-18.

[39] Redefer, L. A., \& Goodman, J. F. (1989). Brief report: Pet-facilitated therapy with autistic children. Journal of Autism and Developmental Disorders, 19, 461-467.

[40] Nathanson, D. E., de Castro, D., Friend, H., \& McMahon, M. (1997). Effectiveness of short-term dolphin-assisted therapy for children with severe disabilities. Anthrozoös, 10, 90-100.

[41] Daly, B. and Morton, L. L. 2003. Children with pets do not show higher empathy: A challenge to current views. Anthrozoös 16: 298-314.

[42] Beth Daly \& L.L. Morton (2006) An investigation of human-animal interactions and empathy as related to pet preference, ownership, attachment, and attitudes in children, Anthrozoös, 19:2, 113-127, DOI: 10.2752/089279306785593801.

[43] Baron-Cohen, S. and Wheelwright, S. 2004. The empathy quotient: An investigation of adults with Asperger Syndrome or high functioning autism, and normal sex differ- ences. Journal of Autism and Developmental Disorders 34: 163-175.

[44] Gawronski, I. and Privette, G. 1997. Empathy and reactive depression. Psychological Reports 80: 1043-1049.

[45] Eisenberg, N. and Lennon, R. 1983. Sex differences in empathy and related capacities. Psychological Bulletin 94: $100-131$. 
[46] Kaiser, L., Spence, L. J., Lavergne, A. G. and Bosch, K. L. 2004. Can a week of thera- peutic riding make a difference? A pilot study. Anthrozoös 17: 63-72.

[47] Paul, E. S. and Serpell, J. A. 1993. Childhood pet keeping and humane attitudes in young adulthood. Animal Welfare 2: 321-337.

[48] Robert H. Poresky,1 Charles Hendrix, 1987, The Companıon Anımal Bondıng Scale: Internal Relıabılity And Construct Valıdity Psychological Reports, 60, 743-746.

[49] Hydek, . R.. Kurdekl,., \& Larson. P. (1983) Relationsip between pet owner ship and self-esteem, social sensitivity. and interpersonal trust. Psychological Repom, 42,110.

[50] Vlasta Vizek Vidović, Vesna Vlahović Štetić \& Denis Bratko (1999) Pet Ownership, Type of Pet and SocioEmotional Development of School Children, Anthrozoös, 12:4, 211-217, DOI: 10.2752/089279399787000129.

[51] Carri Westgarth, Lynne M Boddy, Gareth Stratton, Alexander J German, Rosalind M Gaskell, Karen P Coyne, Peter Bundred, Sandra McCune and Susan Dawson, 2013, Pet ownership, dog types and attachment to pets in 9-10 year old children in Liverpool, UK, Westgarth et al. BMC Veterinary Research, 9:102.

[52] Siegel JM: Pet ownership and the importance of pets among adolescents. Anthrozoös 1995, 8(4):217-223.

[53] Rebecca Purewal, Robert Christley, Katarzyna Kordas, Carol Joinson, Kerstin Meints, Nancy Gee and Carri Westgarth, 2017, Companion Animals and Child/Adolescent Development: A Systematic Review of the Evidence, International Journal of Environmental Research and Public Health, 14, 234; doi:10.3390/ijerph14030234.

[54] Roxanne D. Hawkins, Joanne M. Williams and Scottish Society for the Prevention of Cruelty to Animals (Scottish SPCA) 2017, Childhood Attachment to Pets: Associations between Pet Attachment, Attitudes to Animals, Compassion, and Humane Behaviour, International Journal of Environmental Research and Public Health, 14, 490; doi:10.3390/ijerph14050490.

[55] Marsa-Sambola, F.; Williams, J.; Muldoon, J.; Lawrence, A.; Connor, M.; Currie, C. 2017, Quality of life and adolescents' communication with their significant others (mother, father, and best friend): The mediating effect of attachment to pets. Attach. Hum. Dev. 19, 278-297. 